\section{BASIC-PLUS program for one-way and two-way within-subjects ANOVAs with post hoc Newman-Keuls}

\section{RICHARD DENI}

John F. Kennedy Center for Research on Education and Human Development, Peabody College, Nashville, Tennessee 37203

The BASIC-PLUS program described here is interactional, allowing the user to perform data input and analysis from a terminal keyboard. The analyses available are (1) one-way within-subjects ANOVA and (2) two-way within-subjects ANOVA (Bruning \& Kintz, 1968, p. 43; Linton \& Gallo, 1975, p. 166). In both cases all possible post hoc comparisons are made using Newman-Keuls.

Program Input. The user first selects the analysis required, one-way or two-way, then selects whether or not to receive instructions for tabling raw data. These instructions ask the user to order raw scores into a contingency table, where each row holds one subject's data and each column holds scores for each treatment or combination of treatments. The user is then asked to input the number of subjects and the number of levels of each treatment variable. The user types in each subject's data, proceeding along each row of the contingency table from left to right. Following data input, the user must specify a printfile name. All output is placed in that printfile for later printing on a line printer or other print device.

Output. Program output is set for a print device with at least a 132-character/line capacity. However, the perline capacity can be specified by the user. The complete

Preparation of this report was supported by NICHHD Grant 00973. I thank John Moore for his assistance in preparing this report. raw data contingency table is printed with brief variable headings. Summary means are included in the table along with standard deviations. A second table containing the ANOVA summary information (sources of variance, sum of squares, $F$ ratios, etc.) is printed. Finally, a third table is printed containing a matrix depicting all possible post hoc comparisons and their q values.

Language and Computer. The program was written in BASIC-PLUS (Digital Equipment Corporation, 1975) and was developed on a DEC PDP-11/40 computer under the RSTS/E operating system.

Limitations. Since the program uses one-dimensional and two-dimensional arrays, the number of subjects and the number of levels of each variable are limited. In the present version these limits are as follows: (1) up to and including 20 subjects and (2) levels of Treatment A multiplied by levels of Treatment B must not exceed 20.

Availability. A program listing is available without charge from Richard Deni, Box 154, Peabody College, Nashville, Tennessee 37203.

\section{REFERENCES}

Bruning, J. L., \& Kintz, B. L. Computational handbook of statistics. Glenview, Ill: Scott, Foresman, 1968.

Digital Equipment Corporation. Basic-plus language manual. Maynard, Mass: Author, July 1975.

Linton, M.. \& Gallo, P. S., JR. The practical statistician: Simplified handbook of statistics. Belmont, Calif: Brooks Cole, 1975.

(Received for publication January 27, 1977; accepted February 1, 1977.) 